\title{
Incidence of pelvic trauma and relative risk factors for mortality: a population based study in Iran
}

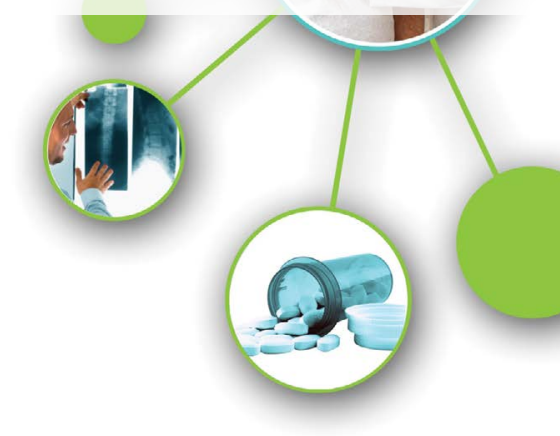

Background: Pelvic trauma (PT) constitutes one of the most devastating injuries in musculo-skeletal trauma. Early treatment and focusing on predisposing factors predicting mortality are essential. We tried to investigate distribution of demographics pelvic trauma, its various causes ,types, fracture sites, associated injuries, and risk factors for mortality on a population basis.

Methods: Of 68102 patients with pelvic trauma, 68000 patients were included for the final analysis. Information about all patients with any ICD-9-CM coded as pelvic injury was retrieved as part of a claims dataset. Based on Revised Trauma Score (RTS), Injury Severity Score (ISS) and Age, Trauma - Injury Severity Score (TRISS) was recorded as predictors of survival rate.

Results: The incidence rate PT is $13.9 / 100,000$ person years (9.9/100,000 for male, 4/100,000 for female). The highest incidence rate PT was in the age 46-60 years group. The highest mortality rate PT happened in the age group more than75 years. The mean length of stay was 8.5 days (females, $7.4 \pm 1.3$ days; males, $9.2 \pm 3.5$ days; $p<0.02$ ). The trauma indices showed that PT had significantly higher mean AIS in the abdomen> chest $>$ head $>>$ multiple pelvic fracture as well as higher average ISS. They also showed lower mean RTS and lower mean probability of survival (TRISS). The most common causes of mortality of PT were massive hemorrhage (42\%) and the second was multiple pelvic fractures. (39\%) Also, demographic characters such as male gender $(P<0.02)$, age $>75$ years $(P<0.03)$, smoking $(P<0.05)$, automobile accident $(\mathrm{P}<0.05)$ set the patient at risk of mortality.

Conclusion: The overall incidence rate of pelvic trauma was higher in the older age male and in low socioeconomic level. Also, massive bleeding, multiple pelvic fractures, coagulopathy problems and injury-related abdominal injuries were stronger positive predicting factors for mortality.

\section{Keywords: pelvic trauma, risk factor, mortality, Iran}

\section{Introduction}

Pelvic fractures usually result from high energy trauma and in approximately $90 \%$ of cases there are associated injuries [1,2]. Pelvic fractures range in severity from low-energy, relatively benign injuries to life-threatening, unstable fractures. Pelvic fractures frequently cause injury to organs contained within the bony pelvis. In addition, trauma to extra pelvic organs is common. Pelvic fractures are often associated with severe hemorrhage due to the extensive blood supply to the region [3-9]. The ring formed by the fused bones of the ischium, ilium and pubis attaches to the sacrum and contains vital structures including major blood vessels and nerves and digestive and reproductive organs. Major pelvic fractures can therefore be catastrophic, mainly due to blood loss. They result from very high-energy trauma such as those generated in road traffic accidents, crush injuries or falls from height. Major pelvic injuries can be devastating and are often associated with a number of complications that may require extensive rehabilitation. Pelvic trauma deaths frequently occur as a result of associated injuries and complications rather than the pelvic injury itself $[10,11]$. Blunt pelvic trauma with unstable pelvic fractures and related late impairments has been reported to significantly affect morbidity as long as one year after the injury [12]. A study in the UK reported that $20 \%$ of seriously injured blunt-trauma patients associated with pelvic fracture [13]. Other studies have reported pelvic fracture mortality rates that vary from 5 up to $50 \%$ in open pelvic fracture [14-19]. In Australia, pelvic fractures have placed a growing demand on healthcare resources and costs over the past 10 years [20]. In Taiwan, the incidence
Keykhosro

Mardanpour ${ }^{* 1}$, Nyoush Mardanpour ${ }^{2}$, Mahtab Rahbar ${ }^{3}$ \& Elham Zarei ${ }^{4}$

${ }^{1}$ Orthopedic Surgeon, Iran University of medical sciences, Iran

${ }^{2}$ General Practitioner, Iran University of medical sciences, Iran

${ }^{3}$ Pathology department of Iran University of medical sciences, Iran

${ }^{4}$ Radiology department of Iran university of medical sciences, Iran

*Author for correspondence:

ezarei@gmail.com 
rate of pelvic fracture was higher in females over 44 years of age. Associated injuries were stronger positive factors for the risk of mortality than gender, fracture sites, injury mechanisms [21]. However, because pelvic fracture leads to an increased health burden and the lengths of hospital stays as long as total inpatient medical costs. Epidemiological information as well as the predictors for mortality in pelvic fracture is deserved for each country. However, data about epidemiological information of pelvic fracture, such as prevalence, distribution of fracture sites and associated injuries, risk factors of mortality are not well documented in recent Asian studies. We aimed to investigate the epidemiology of pelvic fracture in west of Iran population and to look at the risk factors associated with mortality.

\section{Methods}

The study data of 220102 trauma patients were collected in trauma center department of Kermanshah University of medical sciences from May 2011 to March 2017 and prospectively reviewed. Of 68102 patients with pelvic trauma, 68000 patients were included for the final analysis. Data that were collected included: (1) the patient's demographic profile(2), mechanisms of injury (3), Type of pelvic fractures(classified according to the Tile classification)(4), Chronic comorbidities(5), associated injuries(6), injury severity (7) pelvic fracture severity (8), the presence of associated injuries (classified according to AIS)(9), interventions received (10) Socio-Economic levels(11), length of stay in the hospital (12) mortality upon one month after discharge(13) and finally risk factors of mortality (14). Patients were stratified into 6 age groups $:<15$, 15-30, 31-45, 46-60, 61-75 and >75 years old. External morbidity and associated injuries were inferred from the ICD-9-CM codes declared in the same admission data file. Annual inpatient claim files with any diagnostic ICD codes in the 808 range (808.00-808.99), defined as fracture of pelvis, were included in this study. E-codes were classified into groups and represented five common injury mechanisms, such as automobile accident, motorcycle accident, Biker, Pedestrian hit by car, fall from a height. Fracture sites, such as the sacrococcygeal, pubis, ilium, ischium, acetabulum and open pelvic fracture were categorized. Also, liver, renal and endocrine diseases, cancer, diabetes, hypertension, cardiovascular diseases, osteoporosis and other chronic disease were grouped as variables chronic comorbidities. Head injuries (including neck and cervical spine), Chest injuries (including thoracic spine and diaphragm), abdominal injuries (including abdominal organs and lumbar spine), face injuries (including the facial skeleton, nose, mouth, eyes and ears) and extremities fractures were grouped as associated injuries variables. Trauma and injury severity score (TRISS), introduced in 1981, is a combination index based on Trauma Score (RTS), Injury Severity Score (ISS), and patient's age $[22,23]$. The revised trauma score is made up of a sum of results from three categories; Glasgow Coma Scale, Systolic blood pressure, and respiratory rate. The score ranges from 0-12. The Injury Severity Score (ISS) is an anatomical scoring system that provides an overall score for patients with multiple injuries. Each injury is assigned an Abbreviated Injury Scale (AIS) score and is allocated to one of six body regions (Head, Face, Chest, Abdomen, Extremities (including Pelvis), External). The AIS is a consensus derived, anatomically based system of grading injuries on an ordinal scale ranging from 1 (minor injury) to 6 (Lethal injury) [24]. The ISS is defined as the sum of squares of the highest AIS grade in the 3 most severely injured body regions. Six body regions are defined, as follows: The thorax, abdomen and visceral pelvis, head and neck, face, bony pelvis and extremities, and external structures. Only one injury per body region is allowed. The ISS ranges from 1-75, and an ISS of 75 is assigned to anyone with AIS of 6. Patient was clinically assessed and managed as per the $\mathrm{ABC}$ protocol (Airway, Breathing and Circulation). After stabilizing the patient, detailed history was recorded and general physical/systemic examination was done. The following RTS, ISS and age were determined for calculating TRISS [25]. TRISS determines the probability of survival (PS) of a patient from the ISS and RTS. Overall mortality for patients with pelvic trauma was upon 30 days after discharge. Appropriate informed consent and demographic data obtained for filling 22-item questionnaire and cooperation for serial visits after medical intervention. Also, the study was approved by faculty members of trauma center of two educational hospitals ethics committee.

\section{Statistical analysis}

All statistics were calculated with SPSS (version 16.0; SSS Inc. Chicago, II). 
Descriptive statistics included means and standard deviations for continuous variables and frequencies and percentages for discrete variables. Student's t-test and $\chi 2$ test were used to look for associations between variables where appropriate. Multivariate analysis using logistic regression was performed to evaluate significant predictors (determined on univariate analysis) that were associated with mortality. A critical $\mathrm{p}$ value of 0.05 was used for all hypothesis testing.

\section{Results}

We reviewed the records of 68000 patients with PT who admitted during the period from May 2011 to March 2017. The incidence rate was $13.9 / 100,000$ person years $(9.9 / 100,000$ for male, $4 / 100,000$ for female). The comparison of the incidence of PT between gender and age groups is illustrated in FIGURE 1. More males $[n=54800(80 \%)]$ than females $[n=13200(20 \%)]$ were admitted to the hospitals. The common fractures were different between genders and ages. The acetabulum and pubis was more commonly injured in males $(32 \%, 31.5 \%)$ with age group 46-60 years old, and the Sacrococcygeal fracture and Multiple pelvic fractures in females $(28 \%, 18.5 \%)(\mathrm{P}<0.05$ and $\mathrm{P}<0.03$ respectively $)$ with age group $61-75$ years old. $(\mathrm{P}<0.02$ and $\mathrm{P}<0.03$ respectively) In high $\mathrm{BMI}$ patients, the female $(n=3315)$ showed more evidence of pelvic trauma than male $(\mathrm{n}=8891)$. $(\mathrm{P}<0.04)$ The male patients with non-injury-related cardiovascular disease and hypertension showed more evidence of pelvic trauma than female $(\mathrm{P}<0.04, \mathrm{P}<0.03$ respectively) and the female with non-injuryrelated diabetes and Osteoporosis showed more evidence of pelvic trauma than male $(\mathrm{P}<0.05$, $\mathrm{P}<0.03$ respectively). The average age of patients with PT was $49.5 \pm 19.8$ years (range, 13-79 years old), and the mean of length of stay in hospital was 8.5 days (females, $7.4 \pm 1.3$ days; males, $9.2 \pm 3.5$ days; $\mathrm{p}<0.02$ ). The acetabulum was the most common pelvic fracture sites (30\%) and the pubis was the second most common $(25 \%)$. Hypertension $(\mathrm{N}=316)$ was the most common non-injury-related comorbidities and the diabetes was the second most common $(n=280) .55983$ patients had injury-related abdominal injuries (82\%), 28502 patients had injury-related chest trauma(42\%) and 19182 patients had injury-related head (except for simple brain concussion) trauma (28\%) that were the first, second and third most common pelvic fracture-related injuries, respectively. Patient demographics, associated injuries, and correlated information, including mortality rate are illustrated in TABLE 1. Patient stratified in six groups mentioned above. The highest incidence rate of PT was found in the 46-60 years group (8.39/100,000 population), and the highest mortality rate was in male $(\mathrm{P}<0.02)$ in age group more than 75 years old. $(\mathrm{P}<0.03)$ The patients with low socioeconomic level showed a higher mortality $(25 \%)$ than in low socioeconomic level respectively $(\mathrm{p}<0.42)$. Automobile accident injuries were the most common cause of PT(37\%), followed by injuries to Motorcycle accident (28\%). Biker was the lowest mechanism of pelvic injury (1\%). The highest mortality was happened in patients with automobile accident injuries. $(\mathrm{P}<0.05) 1661(2.5 \%)$ patients had active and massive hemorrhage that was the most risk factor of PT mortality $(\mathrm{P}<0.00) .10272(15 \%)$ patients had active and multiple pelvic fracture that was the second risk factor of PT mortality $(\mathrm{P}<0.00)$. There were 1043(1.5\%) patients with coagulopathy problems such as DIC and emboli that showed one of the essential predicting factor of PT mortality $(\mathrm{P}<0.05)$. The relationship

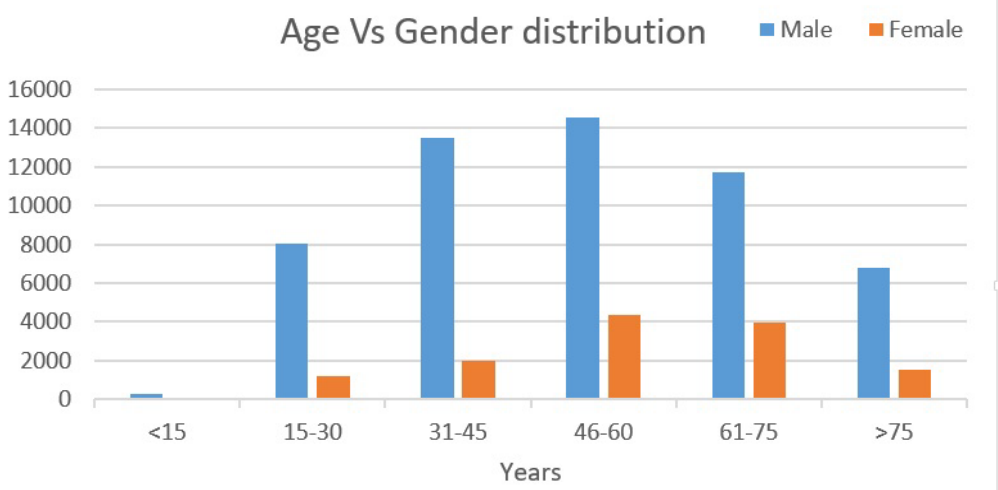

FIGURE 1. Age vs. gender distribution. Comparison of the incidence of pelvic fracture between gender and age groups. 


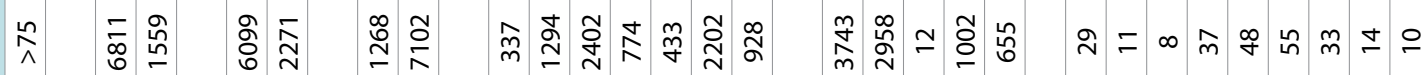

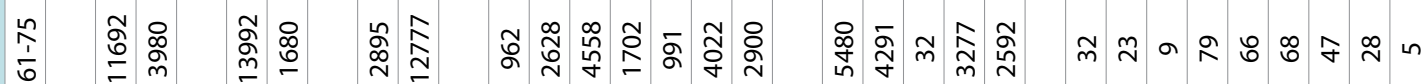

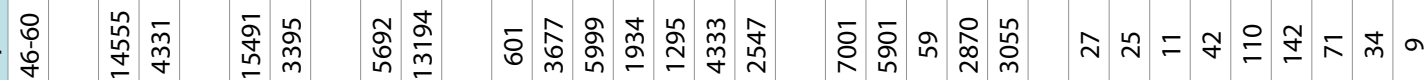

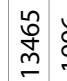

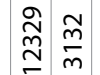

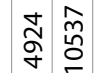

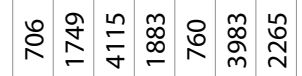

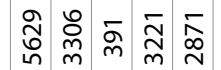

สำำ

in

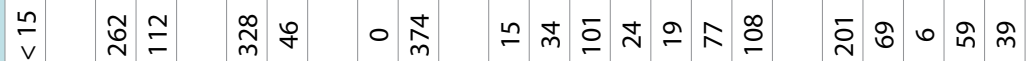

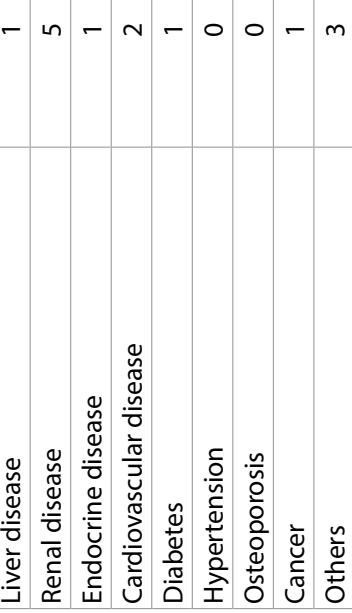




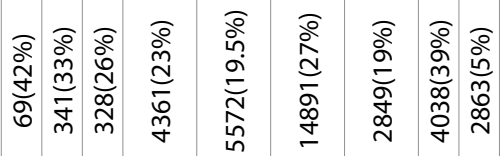

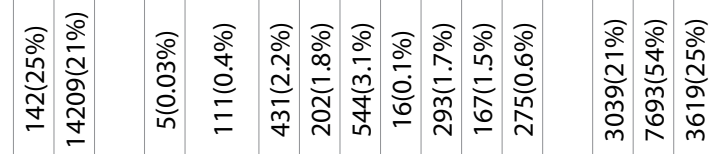

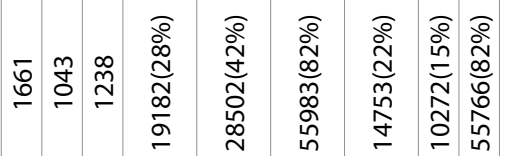

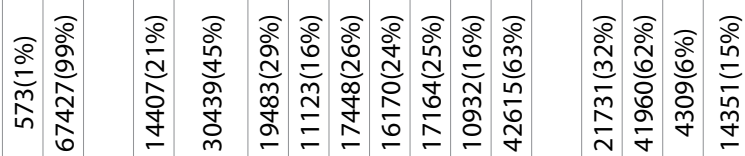

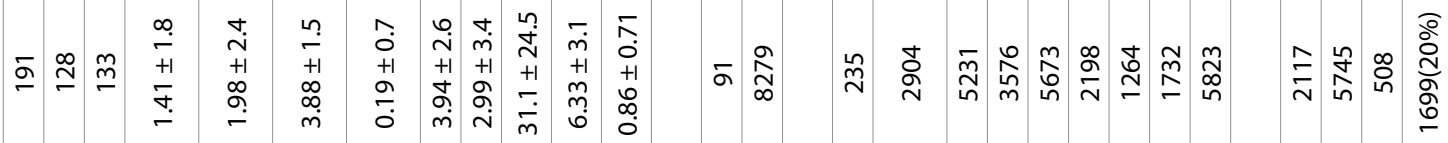

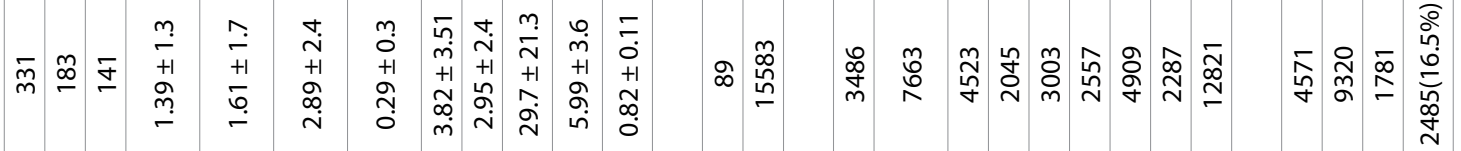

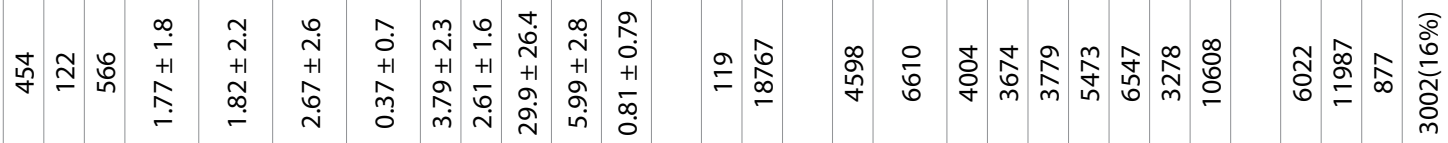

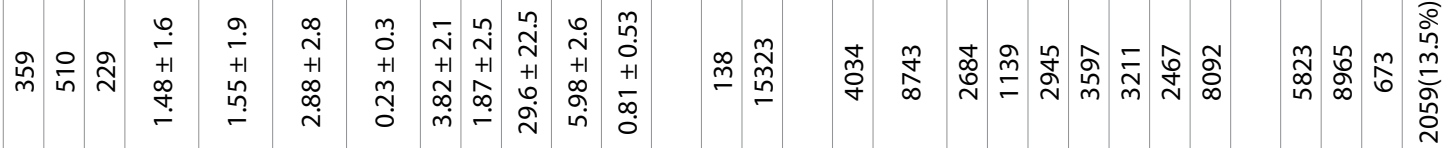

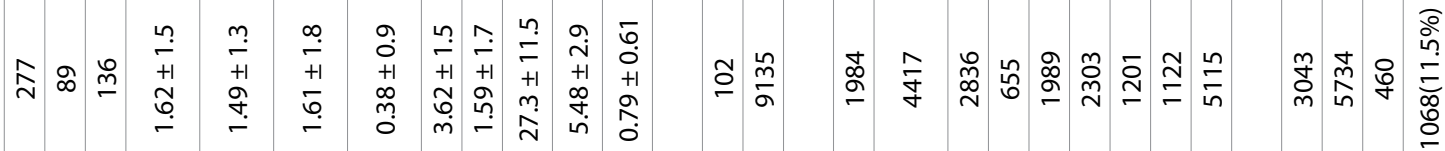

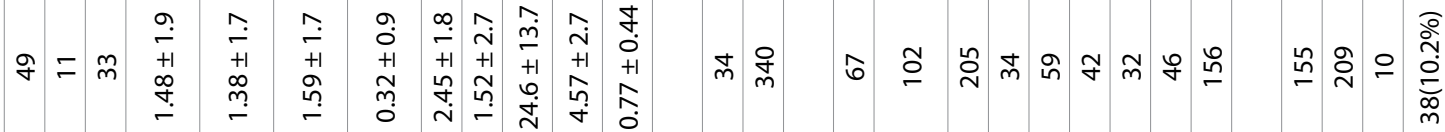

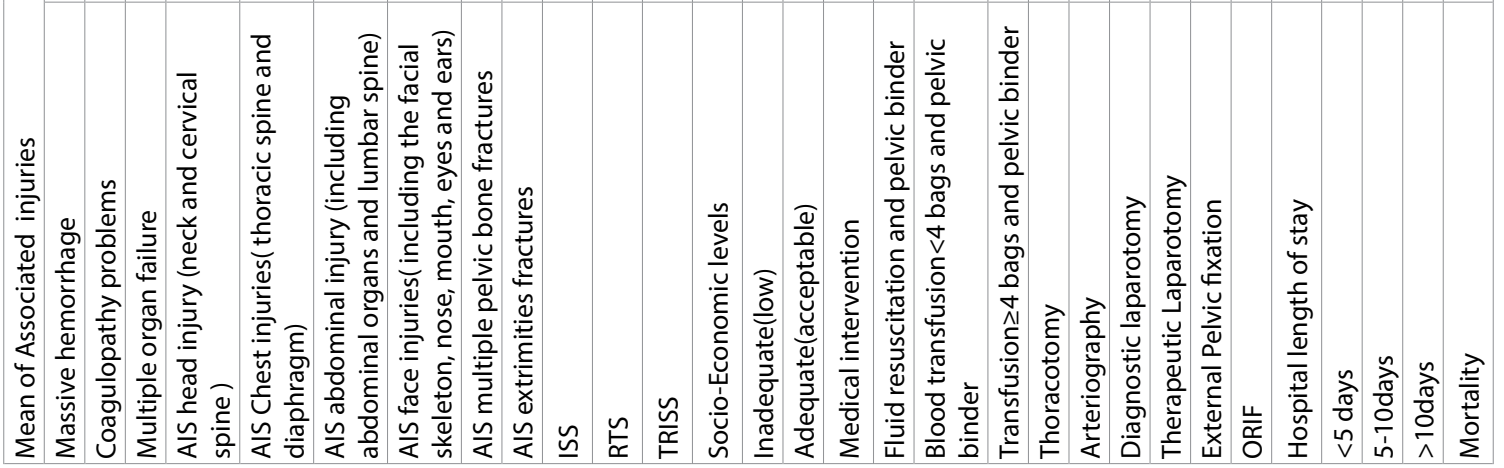


between mortality risk and all these factors were analyzed by using logistic regression, and the results are listed in TABLE 2 . The most common leading cause of death within 6 hours was massive hemorrhage; 6 to 24 hours head injury, and greater than 24 hours multiple organ failure.

On arrival to the emergency department, the orthopedic trauma surgeon performed direct assessment and management. Almost, all patients that faced to hemodynamic instability. 68000 patients had pelvic fractures, and 19483 patients $(29 \%)$ were transfused with more than four units of blood. Following chest trauma, 11123 patients (16\%) received thoracotomy had hemothorax. Following injury-related abdominal injuries, 16170 patients (24\%) received diagnostic laparotomy had hemoperitoneum. 17164 patients $(25 \%)$ had therapeutic laparotomy. 5107 patients $(9 \%)$ received peritoneal lavage and 33429 patients $(60 \%)$ received abdominal operations. $17448(26 \%)$ who continued to be unstable hemodynamically, taken arterial angiography and embolization. After the patient was hemodynamically stabilized, full imaging (including inlet, outlet, Judet, and CT scan) performed. 43547 patients with unstable pelvic fracture (Tile B or C) who operated using open reduction and internal fixation $(63 \%)$ or external fixator or a pelvic C-clamp (16\%) (if posterior instability exists) (TABLE 1). The overall mortality rate was $15 \%(\mathrm{n}=14351)$. The average hospital long of stay for mortality cases was $6.1 \pm 2.2$ days, which was shorter than the total average hospital long of stay of patients (8.3 \pm 3.7 days). There were no significant differences between the numbers of patients in each year during of these 6 years $(p>0.65)$. (FIGURE 2) One-way analysis of variance (ANOVA) showed a significant difference in the spring and summer incidence of pelvic fracture with a higher incidence rate in the fall and winter $(\mathrm{p}<0.04)$ (FIGURE 3).

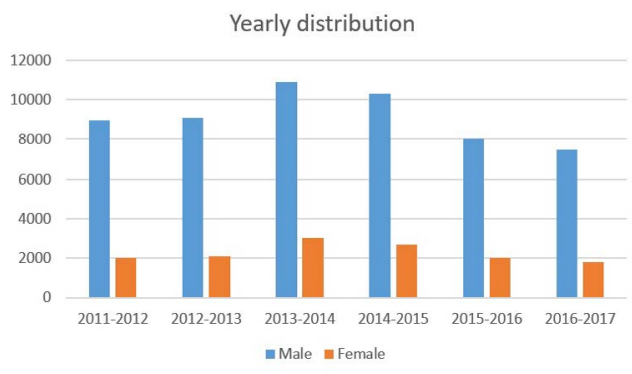

FIGURE 2. Yearly distribution of pelvic fracture..

Table 2: Logistic Regression for Predictors of Mortality among Patients with Pelvic Ring Fractures .(Cl: confidence interval)

\begin{tabular}{|c|c|c|}
\hline Variables & Odds ratio $(95.0 \% \mathrm{CI})$ & P value \\
\hline Male & $2.814(21.749-2.880)$ & 0.02 \\
\hline $\mathrm{BMI} \geq 25$ & $1.135(1.090-1.181)$ & 0.42 \\
\hline smoking & $0.169(0.160-1.678)$ & 0.05 \\
\hline 46-60years & $0.986(0.961-1.012)$ & 0.08 \\
\hline 61-75years & $1.158(1.125-1.192)$ & 0.06 \\
\hline$>75 y e a r s$ & $2.281(2.145-2.426)$ & 0.03 \\
\hline Sacrococcygeal & $0.189(0.160-0.618)$ & 0.82 \\
\hline pubis & $2.40(2.195-2.286)$ & 0.67 \\
\hline Acetabulum & $1.059(1.033-2.185)$ & 0.05 \\
\hline Open pelvic fracture & $2.230(1.923-2.920)$ & 0.03 \\
\hline Multiple pelvic fractures & $2.151(2.115-2.189)$ & 0.00 \\
\hline Cardiovascular disease & $1.127(1.090-1.166)$ & 0.03 \\
\hline Diabetes & $0.924(0.911-1.738)$ & 0.04 \\
\hline Hypertension & $1.603(1.583-1.617)$ & 0.01 \\
\hline Osteoporosis & $0.917(0.870-0.976)$ & 0.02 \\
\hline Multiple organ failure & $2.820(2.723-2.920)$ & 0.00 \\
\hline Head injury (neck and cervical spine ) & $3.073(3.048-3.098)$ & 0.00 \\
\hline Chest injuries( thoracic spine and diaphragm) & $2.850(2.831-2.870)$ & 0.01 \\
\hline Abdominal injury (including abdominal organs and lumbar spine) & $4.801(4.770-4.832)$ & 0.00 \\
\hline face injury & $1.727(1.790-2.126)$ & 0.04 \\
\hline Massive bleeding & $3.276(3.260-3.292)$ & 0.00 \\
\hline Coagulopathy & $1.959(1.933-2.185)$ & 0.05 \\
\hline Low Socio-Economic levels & $0.092(0.052-0.133)$ & 0.42 \\
\hline Hospital LoS & $0.289(0.260-1.318)$ & 0.34 \\
\hline Cause of pelvic trauma(Automobile accident) & $1.279(1.260-1.299)$ & 0.05 \\
\hline
\end{tabular}




\section{Monthly distribution of pelvic fracture}

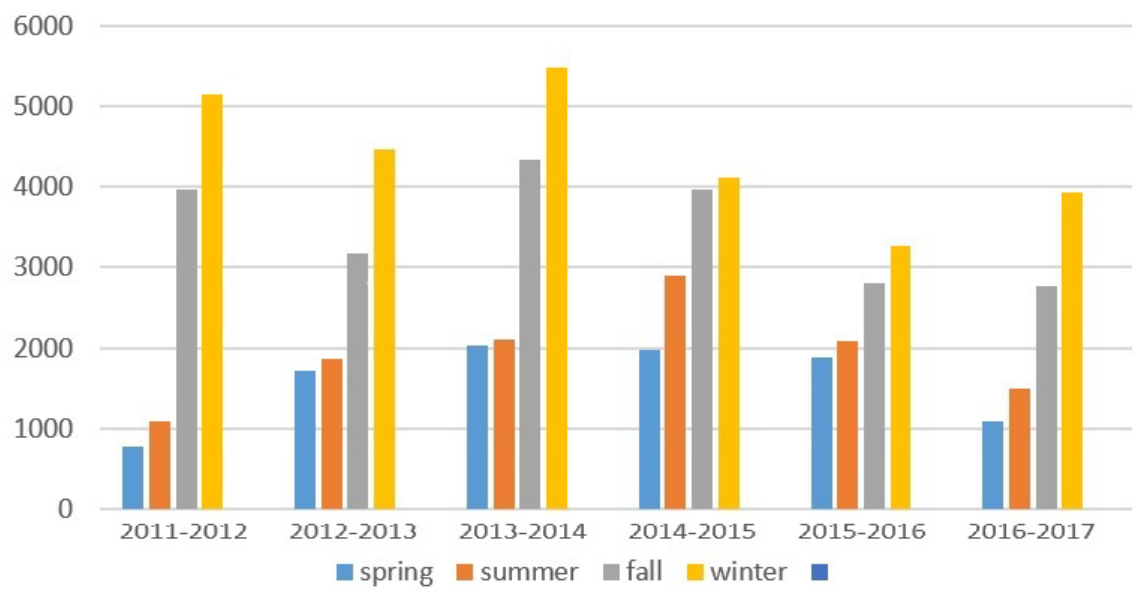

FIGURE 3. Monthly distribution of pelvic fracture

\section{Discussion}

The growing use of motor vehicles and the increasing size of the elderly population, osteoporosis-related fractures will increase pelvic fracture. Therefore, pelvic fracture will become more prevalent and a more burdensome national healthcare problem $[13,21,25,26]$. Because patients with pelvic fractures who are in shock at presentation have high mortality. However, measuring the incidence of pelvic fracture and the risk factors of associated mortality are deserved. Pelvic fractures represent approximately 3 percent of skeletal injuries [27]. Open pelvic fractures are rare and represent only $2-4 \%$ of all pelvic fractures [28]. Of all pelvic ring fractures, approximately $55 \%$ are stable, whereas $25 \%$ have rotational instability, and $20 \%$ have rotational and vertical instability. Approximately $16 \%$ of patients have associated acetabular fractures [29]. Overall mortality from pelvic fractures ranges from 5 to 16 percent, with the rate for unstable pelvic fractures approximately 8 percent [30,31]. The mortality rate associated with acetabular fractures is 3 percent $[8,32]$, while open pelvic fractures, which comprise 2 to 4 percent of all pelvic fractures, are associated with a mortality rate of up to 45 percent [33,34]. Most fatalities stem from associated internal injuries; deaths attributed solely to pelvic fractures range from 0.4 to 0.8 percent of trauma fatalities [31,34]. Patients aged greater than 65 with pelvic fractures have a mortality rate of approximately 20 percent [35]. Overall, pelvic fractures are associated with an increased risk of death among trauma patients [36,37]. An Australian study of pelvic ring fractures demonstrated an incidence of 23 per 100,000 persons per year, while a British study found the incidence of acetabular fractures to be 3 per 100,000 persons per year [38,39]. A study of a large patient database in the United States found that around $70 \%$ of patients sustaining pelvic ring fractures are female [40]. A trauma registry review from New South Wales, Australia, revealed that most patients sustaining high-energy pelvic ring fractures, such as from a motor vehicle crash, were male, whereas females predominated in low-energy injuries [41]. Males also sustain associated genitourinary injuries more commonly than females [42]. Our study showed that most patients sustaining high-energy pelvic ring fractures, such as automobile accident that were male aged more than 46 years old. Also sustain associated head; chest and abdominal injuries more commonly happened in males. In the United States, a large patient database review found that the mean age of patients sustaining a pelvic ring fracture is about 65 years. The average age actually increased significantly over the 17-year study period, which may represent an increase in lowenergy pelvic fractures [40]. A study showed an increasing incidence of severe pelvic fracture in motor vehicle collisions in Ontario, Canada, from 3.9 to $7.5 \%$ in 10 years [25]. One study in Taiwan reported that the incidence rate of pelvic fracture was higher in females over 44 years of age. Associated injuries were stronger positive factors for the risk of mortality than gender, fracture sites, injury mechanisms, and the characteristics of the treating hospitals [43]. In an 11-year retrospective study [44], 
$236(30.4 \%)$ sacral fractures were identified among 776 pelvic injuries. Reviews of two large trauma registries found the incidence of pelvic ring fractures among admitted trauma patients to be 8 and 9.3 percent, respectively $[17,44]$. Risk factors for pelvic fractures include low bone mass, smoking, hysterectomy, older age, and a propensity to fall [45]. We reported the incidence, the distribution of pelvic fracture sites and types and the differences between genders. We found a high incidence of pelvic fracture for the elderly male. Also we also illustrated that more than the patients were between 46 to 60 years old. A predominance of female population among those with pelvic fracture has been reported since the 1980s $[45,46]$. We found that more female patients were among the age groups over 46 years old. A probable explanation is that osteoporosis is more severe in older women than in men in general [47].

We also reported that our female patients had higher BMI, more sacrococcygeal and multiple pelvic fractures, more noninjuryrelated osteoporosis and diabetic disease. Also, female patients showed shorter LOS than male patients. Additionally, we found a higher incidence rate of pelvic fracture admissions at our trauma center in the colder season. One study of the literature showed substantial annual variation [48] but some studies reported that seasonal variations didn't effect on admissions of pelvic trauma patients significantly [49-51]. Automobile accident was a significant factor for the risk of death. In Taiwan population, none of the mechanisms mentioned above was a significant factor for the risk of death [43] but one study showed that automobile accidents increased the risk of mortality and reported that the cause of death in most trauma mortalities with pelvic fractures was primarily associated injuries, not pelvic fractures alone [34]. Our study showed that the most causes of mortality with pelvic trauma were massive uncontrolled bleeding and multiple pelvic fractures.

Our study showed that Pelvic trauma related head injuries, such as skull fracture and intracranial hemorrhage, significantly increased the risk of death in patients with pelvic fracture. Furthermore, our results also revealed that associated face, chest and abdominal injuries significantly increased the mortality risk. Patients who had open pelvic fractures, acetabulum and multiple pelvic fractures or received a blood transfusion of more than four units were also at a greater risk of death. However, our study revealed that coagulopathy problem such as emboli or DIC and some noninjury-related comorbidity like cardiovascular and diabetic diseases and hypertension put our patients in risk of mortality significantly. The limitation of this study was patients who died at home during at one month after discharge based on a traditional idea that dying patients should be taken home to die. However, for this reason, some dying patients didn't record in our study.

\section{Conclusion}

This national survey is essential to understanding the epidemiology and incidence of pelvic trauma in Iran and other developmental societies. The analysis of mortality risk factors should give healthcare providers important information on which to base their decisions. All information should be taken when facing to patients with pelvic trauma. However, more detailed studies are needed.

\section{Conflicts of interest}

No potential conflicts of interest relevant to this article were reported.

\section{Disclosure}

No potential conflicts of interest relevant to this article were reported.

\section{Ethics statement}

Appropriate informed consent and demographic data obtained for filling 22-item questionnaire and cooperation for serial visits after medical intervention. Also, the study was approved by faculty members of trauma center of two educational hospitals ethics committee. 


\section{REFERENCES}

Dalal SA, Burgess AR, Siegel JH, et al. Pelvic fracture in multiple trauma: classification by mechanism is key to pattern of organ injury, resuscitative requirements, and outcome. J. Trauma. 29(7), 981-1000 (1989).

Gustavo PJ, Coimbra R, Rasslan $S$, et al. The role of associated injuries on outcome of blunt trauma patients sustaining pelvic fratures. Injury. 31(9), 677-82 (2000).

Burlew CC, Moore EE, Stahel PF, et al. Preperitoneal pelvic packing reduces mortality in patients with life-threatening hemorrhage due to unstable pelvic fractures. J. Trauma Acute Care Surg. 82(2), 233-242 (2017).

Andrich S, Haastert B, Neuhaus E, et al. Excess Mortality After Pelvic Fractures Among Older People. J. Bone Miner. Res. 32(9), 1789-1801 (2017).

DeFrancesco CJ, Sankar WN. Traumatic pelvic fractures in children and adolescents. Semin. Pediatr. Surg. 26(1), 27-35 (2017).

Caillot M, Hammad E, Le Baron M, et al. Pelvic fracture in multiple trauma: A 67-case series. Orthop. Traumatol. Surg. Res. 102(8), 1013-1016 (2016).

Stahel PF, Hammerberg EM. History of pelvic fracture management: a review. World J. Emerg. Surg. 11, 18 (2016).

Giordano V, Koch HA, Gasparini S, et al. Open Pelvic Fractures: Review of 30 Cases. Open Orthop. J. 10, 772-778 (2016).

Chu CH, Tennakoon L, Maggio PM, et al. Trends in the management of pelvic fractures, 2008-2010. J. Surg. Res. 15(2), 335-340 (2016).

Gansslen A, Pohlemann T, Paul C, et al. Epidemiology of pelvic ring injuries. Injury. 27, S-A13-20 (1996).

Chong $\mathrm{KH}$, DeCoster T, Osler T, Robinson B. Pelvic fractures and mortality. Iowa Orthopaedic J. 17, 110-114 (1997).

TöttermanA, GlottT, SøbergHL, MadsenJE, Røise O. Unstable sacral fractures: associated injuries and morbidity at 1 year. Spine. 31(18), E628-35 (2006).

Muir L, Boot D, Gorman DF, Teanby DN. The epidemiology of pelvic fractures in the Mersey Region. Injury. 27(3), 199204 (1996).

Richardson JD, Harty J, Amin M, FlintL M. Open pelvic fractures. J. Trauma. 22(7), 533-538 (1982).

Flint L, Babikian G, Anders M, Rodriguez J, Steinberg S. Definitive control of mortality from severe pelvic fracture. Ann. Surg. 211(6), 703-707 (1990).

Bassam D, Cephas GA, Ferguson KA, Beard LN, Young JS. A protocol for the initial management of unstable pelvic fractures. Am. Surg. 64(9), 862-786 (1998).

Riemer BL, Butterfield SL, Diamond DL, et al. Acute mortality associated with injuries to the pelvic ring: the role of early patient mobilization and external fixation. J. Trauma. 35(5), 671-677 (1993).

Starr AJ, Griffin DR, Reinert CM, et al. Pelvic ring disruptions: prediction of associated injuries, transfusion requirement, pelvic arteriography, complications, and mortality. J. Orthop. Trauma. 16(8), 553-561 (2002).

Smith W, Williams A, Agudelo J, et al. Early predictors of mortality in hemodynamically unstable pelvis fractures. J. Orthop. Trauma. 21(1), 3137(2007).

Burge R, Dawson-Hughes B, Solomon $\mathrm{DH}$, et al. Incidence and economic burden of osteoporosis related fractures in the United States. J. Bone Miner. Res. 22(3), 465-475 (2007).

Pocock NA, Culton NL, Harris ND. The potential effect on hip fracture incidence of mass screening for osteoporosis. Med. J. Aust. 170(10), 486488 (1999).

Champion HR, Sacco WJ, Carnazzo AJ, Copes W, Fouty WJ. Trauma score. Crit. Care Med. 9(9), 672-676 (1981).

Gennarelli TA, Wodzin E. AIS 2005: A contemporary injury scale. Injury. 37(12), 1083-1091(2006).
Boyd CR, Tolson MA, Copes WS. Evaluating trauma care: The TRISS method. Trauma Score and the Injury Severity Score. J. Trauma. 27(4), 370-378 (1987).

Inaba K, Sharkey PW, Stephen DJ, Redelmeier DA, Brenneman FD. The increasing incidence of severe pelvic injury in motor vehicle collisions. Injury. 35(8), 759-765 (2004).

Boufous S, Finch C, Lord S, Close J. The increasing burden of pelvic fractures in older people, New South Wales, Australia. Injury. 36(11), 1323-1329 (2005).

Grotz MR, Allami MK, Harwood P, et al. Open pelvic fractures: epidemiology, current concepts of management and outcome. Injury. 36(1), 1-13 (2005).

Stein DM, O'Connor JV, Kufera JA, et al. Risk factors associated with pelvic fractures sustained in motor vehicle collisions involving newer vehicles. $J$. Trauma. 61(1), 21-30 (2006).

Rowe SA, Sochor MS, Staples KS, et al. Pelvic ring fractures: implications of vehicle design, crash type, and occupant characteristics. Surgery. 136(4), 842 (2004).

Yoshihara H, Yoneoka D. Demographic epidemiology of unstable pelvic fracture in the United States from 2000 to 2009: trends and in-hospital mortality. J. Trauma Acute Care Surg. 76(2), 380 (2014).

Vaidya R, Scott AN, Tonnos F, et al. Patients with pelvic fractures from blunt trauma. What is the cause of mortality and when? Am. J. Surg. 211(3), 495-500 (2016).

Costantini TW, Coimbra R, Holcomb $\mathrm{JB}$, et al. Current management of hemorrhage from severe pelvic fractures: Results of an American Association for the Surgery of Trauma multi-institutional trial. J. Trauma Acute Care Surg. 80(5), 717-723 (2016).

Dente CJ, Feliciano DV, Rozycki GS, et al. The outcome of open pelvic fractures in the modern era. Am. J. Surg. 190(6), 830-835 (2005).

Hauschild O, Strohm PC, Culemann $\mathrm{U}$, et al. Mortality in patients with pelvic 
fractures: results from the German pelvic injury register. J. Trauma. 64(2), 449 (2008).

Dechert TA, Duane TM, Frykberg BP, et al. Elderly patients with pelvic fracture: interventions and outcomes. Am. Surg. 75(4), 291 (2009).

Sathy AK, Starr AJ, Smith WR, et al. The effect of pelvic fracture on mortality after trauma: an analysis of 63,000 trauma patients. J. Bone Joint Surg. Am. 91(12), 2803-2810 (2009).

Schulman JE, O'Toole RV, Castillo $\mathrm{RC}$, et al. Pelvic ring fractures are an independent risk factor for death after blunt trauma. J. Trauma. 68(5), 930 (2010).

Balogh Z, King KL, Mackay P, et al. The epidemiology of pelvic ring fractures: a population-based study. J. Trauma. 63(5), 1066 (2007).

Kocher MS, Tucker R. Pediatric athlete hip disorders. Clin. Sports Med. 25(2), 241 (2006).

Buller LT, Best MJ, Quinnan SM. A Nationwide Analysis of Pelvic Ring Fractures: Incidence and Trends in
Treatment, Length of Stay, and Mortality. Geriatr. Orthop. Surg. Rehabil. 7(1), 9-17 (2016).

Mackay P. The epidemiology of pelvic ring fractures: a population-based study. J. Trauma. Nov. 63(5), 1066-1073 (2007).

Bjurlin MA, Fantus RJ, Mellett MM, Goble SM. Genitourinary injuries in pelvic fracture morbidity and mortality using the National Trauma Data Bank. J. Trauma. 67(5), 1033-1039 (2009).

Chien LC, Cheng HM, Chen WC, Tsai MC. Pelvic Fracture and Risk Factors for Mortality: A Population-Based Study in Taiwan. Eur. J. Trauma Emerg. Surg. 36(2), 131-137 (2010).

Denis F, Davis S, Comfort T. Sacral fractures: an important problem. Retrospective analysis of 236 cases. Clin. Orthop. Relat. Res. 227, 67-81 (1988).

Melton LJ 3rd, Sampson JM, Morrey BF, Ilstrup DM. Epidemiologic features of pelvic fractures. Clin. Orthop. Relat. Res. 155, 43-47 (1981).

Sanders KM, Nicholson GC, Ugoni $\mathrm{AM}$, et al. Health burden of hip and other fractures in Australia beyond
2000. Projections based on the Geelong Osteoporosis Study. Med. J. Aust. 170(10), 467-470 (1999).

Guggenbuhl P, Meadeb J, Chalès G. Osteoporotic fractures of the proximal humerus, pelvis, and ankle: epidemiology and diagnosis. Joint Bone Spine. 72(5), 372-375 (2005).

Rising WR, O'Daniel JA, Roberts CS. Correlating weather and trauma admissions at a level I trauma center. J. Trauma. 60(5), 1096-1100 (2006).

Töro K, Hubay M, Sótonyi P, Keller E. Fatal traffic injuries among pedestrians, bicyclists and motor vehicle occupants. Forensic Sci. Int. 151(2-3), 151-156 (2005).

Atherton WG, Harper WM, Abrams KR. A year's trauma admissions and the effect of the weather. Injury. 36(1), 40-46 (2005).

Han TH, Kim JH, Yang MS, Han KW, $\mathrm{Han} \mathrm{SH}$, et al. A retrospective analysis of 19,157 burns patients: 18-year experience from Hallym Burn Centerin Seoul, Korea. Burns. 31(4), 465-470 (2005).

\section{This special issue on Current Trends in Clinical Research was edited by Dr. Mohamed Elsayed.}

